\title{
The Effect of Lumbar Lordosis Rehabilitation on S1 Alfa Motor Neuron Excitability in Chronic Non Specific Low Back Pain
}

\author{
HEND I. MOHAMED, M.Sc.*; MOHAMED H. EL-GENDY, Ph.D.*; SALAH EL-DIN B. AHMED, Ph.D.* and \\ AMR ABD-ALLA AZZAM, Ph.D.** \\ The Department of Physical Therapy for Basic Sciences, Faculty of Physical Therapy, Cairo University* and \\ The Department of Orthopedic Surgery, National Institute of Neuromotor System**
}

\begin{abstract}
Background: Chronic Mechanical Low Back Pain (CMLBP) represents a significant public health problem and an economic burden to employers. There is a gap in literature concerning the investigations on changes of the motor nerve excitability during rehabilitation of lumbar lordotic curve which represent a major barrier preventing the exploration of the most effective conservative treatment on restoring the lumbar lordosis. The Denneroll is a relatively new sagittal plane orthotic device designed to passively stretch the lordotic curve into a more lordotic position.
\end{abstract}

Aim of Study: This study designed to study the effect of lumbar Denneroll traction on motor nerve excitability on chronic low back pain patients.

Material and Methods: Thirty patients had participated in this study; they were assigned randomly into two groups (A) experimental group, and (B) control group. Group (A) consisted of 15 patients; they received combined program of Denneroll traction and conservative physical therapy treatment. Group (B) which consisted of 15 patients; they received the same conservative treatment as group (A) in form of (ultrasonic therapy, infrared and stretching exercise). Treatment was given 3 times per week, each other day, for ten consecutive weeks. Patients were evaluated pre-treatment and posttreatment for the H-reflex, $\mathrm{H} / \mathrm{M}$ ratio and Absolute Rotatory Angle (ARA).

Results: Using repeated measures multivariate analysis of variance (MANOVA) test, patients showed significant improvement in the combined dependent variables in both groups but between groups difference group (A) showed a more significant improvement than group (B) in the combined dependent variables. Both of the Denneroll and traditional treatment had a significant effect onthe $\mathrm{H}-$ reflex, $\mathrm{H} / \mathrm{M}$ ratio and absolute rotatory angle indicated that there were significant effects of the tested group (the first independent variable) on the all tested dependent variables; $\mathrm{H}$-reflex, $\mathrm{H} / \mathrm{M}$ ratio and ARA ( $\mathrm{F}=31.357, p=0.0016)$. However, there were significant effects of the measuring periods (the second independent variable) on the tested dependent variables $(\mathrm{F}=114.404$,

Correspondence to: Dr. Hend I. Mohamed, The Department of Physical Therapy for Basic Sciences, Faculty of Physical Therapy, Cairo University $p=0.0001)$. However, the interaction between the two independent variables was significant, which indicates that the effect of the tested group (first independent variable) on the dependant variables was influenced by the measuring periods (second independent variable) $(\mathrm{F}=26.035, p=0.0001)$.

Conclusion: Therefore, the combination of Denneroll with traditional physical therapy treatment program more effective than the therapeutic exercises alone in the treatment of non-specific low back pain patients.

Key Words: Non-specific low back pain - Denneroll - Hreflex - Absolute rotatory angle.

\section{Introduction}

CHRONIC Mechanical Low Back Pain (CMLBP) represents a significant public health problem and an economic burden to employers [1]. CMLBP has become one of the most common problems in industrialized societies; it can affect $80 \%$ of the people and has become the most common cause of functional limitation in individuals younger than 35 years $[2,3]$

Persistent back disorders seriously compromise the quality of work and life. Health care professionals are affected by several painful problems in the back during different modalities application on patients and lifting. Physical therapists are professionals who often present this type of disorder [4]

There is a gap of literature concerning the investigations on changes of the motor nerve excitability during rehabilitation of lumber lordotic curve which represent a major barrier preventing the exploration of the most effective conservative treatment on restoring the lumbar lordosis. Only few non randomized studies were conducted $[\mathbf{5 , 6}]$, none of these studies found increases in lumbar lordosis post-treatment. 
In this regard, [7] introduced a new sagittal plane orthopedic device (Denneroll) designed to passively stretch the lumbar lordosis into a more lordotic position, its unique design allows it to create a 3-point bending extension load on the spine. The Denneroll creates a passive stretch in thedirection of the normal lumbar curve which can affect the motor nerve excitability.

Accordingly, the main aim of the current study was to investigate the effect of lumbar lordosis rehabilitation on motor nerve excitability. The Electromyography (EMG) technique was used for evaluating and recording the H-reflex amplitude and $\mathrm{HM}$ ratio which considered a reliable assessment tool for measuring the motor nerve excitability.

\section{Material and Methods}

Thirty patients with CMLBP participated in the study, conveniently selected from the Outpatient Clinic, Faculty of Physical Therapy, Cairo University, their age ranged from 20 to 40 years with a mean age $(31.9 \pm 4.6)$ years, their mean height was $(170.2 \pm 6.2) \mathrm{cm}$, and their mean weight was $(76.8$ 士7.4) Kg. between March 2017 and April 2018.

The patients were assigned into two groups of equal numbers. Experimental group consisted of 15 patients and control group consisted of 15 patients. The patients would be eligible to participate in the study under the following specific criteria:

\section{Inclusive criteria:}

1-Patients suffered from low back pain for a period over than 3 months.

2- Patients had ARA less than $40^{\circ}$.

Exclusive criteria:

1- Posterior osteophytes.

2- Previous surgery.

3- Spinal deformity.

4- Lower limb difference that may affect global posture.

5- Spinal canal stenosis.

6- Patients suffering from radicular pain.

\section{II- Material and methods:}

\section{A- Evaluation instrumentations:}

1- Main X-ray imaging: Radiographic techniques have been applied to quantify lordosis and evaluate range of motion. X-ray techniques are considered the most accurate clinical method for measuring lordosis since it is not affected by soft tissuevariations among different subjects. Biplanar radiography has been used to quantify motion in three axes and can achieve highly precised measures of vertebral bodies in space [8].

2- EMG device: Tonneis Neuroscreen plus version 1.59, had four channel Electrodignosis system and built amplifier was used to record the H-reflex amplitude and H/M ratio. This apparatus include [9]:

- Amplifier: Four electrically isolated amplifier channels, with impedance less than $100 \mathrm{mv}$ and sensitivity up to $4000 \mathrm{mv}$.

- Stimulating unit: To which the stimulating electrode was connected.

- Electrodes: Ground electrode, bipolar stimulating electrode with inters electrode distance of $2.5 \mathrm{~cm}$ and two silver surface recording electrodes (one is active and the other is the reference). Before the apparatus was used, the commit company calibrated all tested parameters.

\section{B- Treatment measurement:}

1-Denneroll traction device: The Dennerollis a new sagittal planeorthoticdevice, designed to stretch passively the lordotic curve into a more lordotic position. The Denneroll is made from soft, stable polyethylene foam providing cushioning to allow maximal comfort. It can assist in relief of pain, muscle tension, and recovery from disc injury available with two Lumbar sizes adult Medium \& Large [9]; large size was used in this study.

2- Ultrasound therapy device: (EnrafnoniusSonoplus 590) the Sonopulse 590 is a microprocessor-controlled unit for continuous and pulsed U.S therapy. This apparatus allow: $1 \mathrm{MHZ}$ frequency with transducer had an effective radiating area of $5.0 \mathrm{~cm}^{2}$. The treatment time was 15 minutes/ session. Infrared is chosen as a form of heat prior to stretching, mobilization, traction, massage and exercise therapy [10].

\section{Design of the study:}

Non-equivalent control group design was used in the study. Thirty patients were assigned in two groups of equal numbers [11,12]

Experimental group: Included 15 patients received Denneroll traction in addition to traditional physical therapy in form of ultrasound therapy (U.S.T) [13], Infra Red Radiation (I.R.R) [14] and stretching exercise [15]

Control group: Included 15 patients received only traditional physical therapy in form of (U.S.T, I.R.R and stretching exercise). 
For both groups, the treatment was conducted for ten weeks; three sessions per week with the total of 30 sessions [16]. The angle of lumbar lordosis was measured by using plain X-ray, the $\mathrm{H}$-reflex and $\mathrm{H} / \mathrm{M}$ ratio was measured also before and after treatment by EMG.

\section{A- Evaluation procedures:}

1-Measurement of absolute rotatory angle: Standard lateral lumbar radiographs were obtained with patients in standing position with arms folded on the chest placing; the hands in the clavicular fossae, all the posterior-superior and posteriorinferior vertebral body corner on lateral lumbar radiograph were marked and; two tangents drawn at the posterior body margins of LI and L5 were constructed. The absolute rotatory angle is formed by the intersection of the tangents at the posterior body margins of LI and L5 [17]. X-ray was calibrated by the Faculty of Engineering, Cairo University. X-ray for measuring ARA was validated by [18] concluded that X-ray for measuring ARA is reliable.

2- Electrophysiological measurement: Measurement of the $\mathrm{H}$-amplitude and $\mathrm{H} / \mathrm{M}$ ratio was conducted in the Faculty of Physical Therapy, Cairo University. The subjects were allowed to rest for 5 minutes before the beginning of the measurement [19]

- Position of the patient: The patient was placed in prone lying position in quiet room on a wooden padded table to eliminate environmental variations on the EMG. The head was maintained in mid position to control the possible effects of asymmetrical tonic neck reflex.

The examined leg was placed at zero degree of extension and mid-way between abduction and adduction at the hip. The knee was flexed 20 degrees by placing a small cushion under the knee to relax the gastrocnemius muscle to reduce any depressive influence on the H-reflex and the ankle was freely positioned in planter flexion outside the plinth.

- Skin preparation: First step before sensor placement is skin preparation. This includes shaving any excess hair and cleaning the skin with an alcohol pad; abrasion of the skin is also a common step. The goal of all of these steps is to allow for better adhesion of the electrode and the reduction of skin electrical resistance.

- Position of the electrodes: The two surface electrodes were coated with a special electro conductive gel to ensure good electrical coupling. The active recording electrodes was placed over the soleus muscle $2 \mathrm{~cm}$ below the junction of the two heads of gastrocnemius in line with the Achilliestendonwhile the ground electrode was placed on the skin of the lateral side of the calf muscle, equidistant between the stimulating and recording electrodes to minimize the stimulus artifact. The electrodes were fixed to the skin by adhesive plaster.

- Recording of the H-reflex: The H-reflex was elicited by stimulating the posterior tibial nerve at the popliteal fossa using $1.0 \mathrm{~ms}$ (pulse duration) square applied at $0.5 \mathrm{sec}$ (frequency) interval and monitored on line and stored on an oscilloscope. Resolution to $10 \mathrm{mv}$ was used to measure the $\mathrm{H}$ reflex amplitude (peak to peak). Peak to peak $\mathrm{H}$ reflex amplitude and $M$ wave amplitude (10 readings) were displayed as waveforms on the monitor panel.

- The H/M ratio was measured for each subject according to the following sequence: The current intensity is slowly increased until the stimulus just activates the large la afferent fibers without concomitant activation of the motor fibers or just threshold for only motor fibers. The stimulus should be delivered at a rate of 1 stimulus every $2-3 \mathrm{sec}$ to avoid suppressing the H-reflex through central mechanism. The intensity of the stimulation gradually increased to record the maximum $\mathrm{H}$-reflex as well as the maximum $\mathrm{M}$ value. Maximum H-reflex amplitude was manifested when most la fibers excited with the $\mathrm{M}$ response.

\section{B- Treatment procedures:}

1- Ultrasound therapy: Each patient in the two groups received continuous U.S therapy at an intensity of $1.0 \mathrm{~W} / \mathrm{cm}^{2}$, frequency $1 \mathrm{MHZ}$ and $100 \%$ duty cycle. It was applied on paraspinalmuscles. The coupling media were applied to the skin surface to reduce transfer losses and minimize reflection. The treatment head had been placed on the skin before output was turned on. The treatment head moved continuously over the surface while even pressure was maintained in order to iron out the irregularities in the sonic field. A stroking technique was used, where transducer head was moved slowly at the rate of approximately $25 \mathrm{~mm} / \mathrm{s}$ with circular and/or parallel strokes. The duration of application was five minutes per session [12]. Each patient received treatment with U.S.T three sessions per week for ten weeks.

\section{2- Stretching exercise (Hamstring Stretch):}

- Patient position: Supine lying with extended knees. 
- Therapist position: Stride standing with the patient knee fully extended and supported over therapist shoulder.

- Procedure: Stabilize the non stretched lower limb with one hand or with belt, with knee fully extended flex hip as much as possible and hold $30 \mathrm{sec}$ then relax for $30 \mathrm{sec}$ repeated for five times [16].

3- Denneroll traction: The Denneroll orthotic applies a passive 3-point bending force to the lumbar spine that is most consistent with the 2way type traction force,

- Technique: The patient lies flat on the back with knees and legs were bent for comfort and tolerance with thoracic support block under torso to achieve anterior thoracic translation and prevent excessive thoracic spine extension. Over consecutive days, patients should straighten their legs so that maximum stretch on the legs, hips and back muscles can occur. A natural stretch is created as the pelvis tilts forward and the patient is encouraged to relax while lying on the Denneroll. Start with a time period of $3-5 \mathrm{~min}$ and gradually increase reaching $20 \mathrm{~min}$ all that is required to develop a functional stretch effect. Sustained loading periods of 10-20 minutes is necessary to cause visco-elastic deformation to the resting length of the spinal muscles and ligaments $[\mathbf{1 9 , 2 0}$. The Denneroll was applied day after day.

\section{Data collection:}

The data concerning the ARA using plain Xray, $\mathrm{H}$-reflex and $\mathrm{H} / \mathrm{M}$ ratio by EMG were collected at two instances before applying Denneroll traction and at the end of the tenth week.

\section{Data analysis and statistical design:}

The following statistical procedures were conducted as following:

- Descriptive statistics including the mean, standard deviation and percentage of difference of posttreatment data as compared to pre one.

- Inferential statistics by using paired $t$-test for the same group and unpaired $t$-test between the two groups.

\section{Results}

The main purpose of this study was to investigate the effect of lumbar lordosis rehabilitation by Denneroll on motor nerve excitability. Statistical analysis was conducted using SPSS for windows, version 23 (SPSS, Inc., Chicago, IL). The current test involved two independent variables. The first one was the (tested group); between subject factor which had two levels (group A received combined program of Denneroll traction and traditional physical therapy treatment, group $B$ received only the same traditional treatment as group (A) in form of U.S therapy, I.R.R and stretching exercise). The second one was the (measuring periods); within subject factor which had two levels (pretreatment, post-treatment). In addition, this test involved three tested dependent variables (H-reflex, H/M ratio and ARA).

Prior to final analysis, data were screened for normality assumption, homogeneity of variance, and presence of extreme scores. This exploration was done as a pre-requisite for parametric calculations of the analysis of difference. Preliminary assumption checking revealed that data was normally distributed for hip H-reflex, $\mathrm{H} / \mathrm{M}$ ratio and ARA, as assessed by Shapiro-Wilk test $(p>0.05)$; there were no univariate or multivariate outliers, as assessed by boxplot and Mahalanobis distance $(p>0.05)$, respectively; there were linear relationships, as assessed by scatterplot; no multicollinearity. There was homogeneity of variances ( $p>$ $0.05)$ and covariances ( $p>0.05)$, as assessed by Levene's test of homogeneity of variances and Box's M test, respectively. Accordingly, 2 X 2 mixed design MANOVA was used to compare the H-reflex, $\mathrm{H} / \mathrm{M}$ ratio and ARA at different measuring periods at both groups. The alpha level was set at 0.05 .

\section{General characteristics:}

The current study was conducted on 30 participants. They were assigned into two equal groups. Group (A) consisted of 15 participants with mean age value of $34.53 \pm 4.95$ years. Group (B) consisted of 15 participants (Table 1 ).

Table (1): General characteristics of participants in both groups (A and B).

\begin{tabular}{|c|c|c|c|c|c|}
\hline \multirow{2}{*}{ Items } & \multirow{2}{*}{$\begin{array}{c}\text { Group A } \\
\text { Mean } \pm \text { SD }\end{array}$} & \multirow{2}{*}{$\begin{array}{c}\text { Group B } \\
\text { Mean } \pm \text { SD }\end{array}$} & \multicolumn{2}{|c|}{ Comparison } & \multirow{2}{*}{ S } \\
\hline & & & $t$-value & $p$-value & \\
\hline Age (years) & $34.53 \pm 4.95$ & $32.73 \pm 4.68$ & 1.023 & 0.315 & NS \\
\hline Height $(\mathrm{cm})$ & $170.43 \pm 35.81$ & $171.54 \pm 35.67$ & 1.011 & 0.765 & NS \\
\hline Weight $(\mathrm{kg})_{2}$ & $67.54 \pm 15.87$ & $69.47 \pm 16.82$ & 1.23 & 0.654 & NS \\
\hline $\mathrm{BMI}\left(\mathrm{kg} / \mathrm{m}^{2}\right)$ & $23.43 \pm 5.89$ & $24.12 \pm 4.91$ & 1.34 & 0.515 & NS \\
\hline $\begin{array}{l}\text { SD }: \text { Standard } \\
p \quad: \text { Probabili }\end{array}$ & & $\begin{array}{l}\mathrm{S} \\
\mathrm{NS}\end{array}$ & Non & ignificant & \\
\hline
\end{tabular}

\section{- 2 X 2 mixed design MANOVA (overall effect):}

Statistical analysis using 2 X 2 mixed design MANOVA indicated that there were significant effects of the tested group (the first independent variable) on the all tested dependent variables; $\mathrm{H}$ - 
reflex, $\mathrm{H} / \mathrm{M}$ ratio and $\mathrm{ARA}\left(\mathrm{F}=31.357, p=0.0016^{*}\right)$. However, there were significant effects of the measuring periods (the second independent variable) on the tested dependent variables $(\mathrm{F}=114.404$, $p=0.0001 *)$. However, the interaction between the two independent variables was significant, which indicates that the effect of the tested group (first independent variable) on the dependent variables was influenced by the measuring periods (second independent variable $)(\mathrm{F}=26.035, p=0.0001 *)$ (Table 2).

Table (2): The 2 X 2 mixed design Multivariate Analysis of Variance (MANOVA) for all dependent variables at different measuring periods between both groups.

\begin{tabular}{lll}
\hline Source of variation & F-value & $p$-value \\
\hline Groups & 31.357 & $0.0001^{*}$ \\
Measuring periods & 114.404 & $0.0001^{*}$ \\
Interaction & 26.035 & $0.0001^{*}$ \\
\hline
\end{tabular}

$*$ : Significant at alpha level $<0.05$.

- Multiple pairwise comparison tests:

1- H-reflex:

A- Within groups: As presented in (Table 3), within group's comparison the mean \pm SD values of H-reflex in the "pre" and "post" tests were $2.4 \pm$ 1.02 and $0.93 \pm 0.44$ respectively in the group (A). Multiple pairwise comparison tests (post hoc tests) revealed that there was significant reduction of $\mathrm{H}$ reflex at post-treatment in compare to pre-treatment $(p=0.0001 *)$. While, the mean $\pm \mathrm{SD}$ values of $\mathrm{H}$ reflex in the "pre" and "post" tests were $1.92 \pm 1.08$ and $1.25 \pm 0.79$ respectively the group (B). Multiple pairwise comparison tests (post hoc tests) revealed that there was significant reduction of H-reflex at post-treatment in compare to pre-treatment ( $p=$ $0.001 *)$.

Table (3): Mean \pm SD and $p$-values of H-reflex pre and posttest at both groups.

\begin{tabular}{llllll}
\hline H-reflex & $\begin{array}{c}\text { Pre test } \\
\text { Mean } \pm \text { SD }\end{array}$ & $\begin{array}{c}\text { Post test } \\
\text { Mean } \pm \text { SD }\end{array}$ & MD & $\begin{array}{c}\% \text { of } \\
\text { change }\end{array}$ & $\begin{array}{c}p \text { - } \\
\text { value }\end{array}$ \\
\hline Group A & $2.4 \pm 1.02$ & $0.93 \pm 0.44$ & 1.47 & $61.25 \%$ & $0.0001^{*}$ \\
Group B & $1.92 \pm 1.08$ & $1.25 \pm 0.79$ & 0.67 & $34.89 \%$ & $0.001^{*}$ \\
MD & 0.48 & -0.32 & & & \\
$p$-value & 0.231 & 0.198 & & & \\
$*$
\end{tabular}

\footnotetext{
* : Significant level is set at alpha level $<0.05$.

SD : Standard Deviation.

MD : Mean Difference.

$p$-value : Probability value.
}

2- Between groups: Considering the effect of the tested group (first independent variable) on $\mathrm{H}$ reflex, multiple pairwise comparison tests (post hoc tests) revealed that the mean values of the "pre" test between both groups showed no significant differences with $(p=0.231)$. As well as, mul- tiple pairwise comparison tests (post hoc tests) revealed that there was no significant difference of the mean values of the "post" test between both groups with $(p=0.198)$.

\section{2- H/M ratio:}

1- Within groups: As presented in (Table 4), within group's comparison the mean $\pm \mathrm{SD}$ values of $\mathrm{H} / \mathrm{M}$ ratio in the "pre" and "post" tests were $1.15 \pm 0.9$ and $0.75 \pm 0.6$ respectively in the group (A). Multiple pairwise comparison tests (post hoc tests) revealed that there was significant reduction of $\mathrm{H} / \mathrm{M}$ ratio at post-treatment in compare to pretreatment $\left(p=0.0001^{*}\right)$. While, the mean \pm SD values of $\mathrm{H} / \mathrm{M}$ ratio in the "pre" and "post" tests were $0.62 \pm 0.32$ and $0.38 \pm 0.2$ respectively the group (B). Multiple pairwise comparison tests (post hoc tests) revealed that there was significant reduction of $\mathrm{H} / \mathrm{M}$ ratio at post-treatment in compare to pretreatment $(p=0.002 *)$.

2- Between groups: Considering the effect of the tested group (first independent variable) on $\mathrm{H} / \mathrm{M}$ ratio, multiple pairwise comparison tests (post hoc tests) revealed that the mean values of the "pre" test between both groups showed no significant differences with $(p=0.059)$. As well as, multiple pairwise comparison tests (post hoc tests) revealed that there was significant difference of the mean values of the "post" test between both groups with $\left(p=0.04^{*}\right)$ and this significant reduction in favor to group B than group A.

Table (4): Mean \pm SD and $p$-values of $\mathrm{H} / \mathrm{M}$ ratio pre and posttest at both groups.

\begin{tabular}{llllll}
\hline H/M ratio & $\begin{array}{c}\text { Pre test } \\
\text { Mean } \pm \text { SD }\end{array}$ & $\begin{array}{c}\text { Post test } \\
\text { Mean } \pm \text { SD }\end{array}$ & MD & $\begin{array}{c}\% \text { of } \\
\text { change }\end{array}$ & $\begin{array}{c}p \text { - } \\
\text { value }\end{array}$ \\
\hline Group A & $1.15 \pm 0.9$ & $0.75 \pm 0.6$ & 0.4 & $34.78 \%$ & $0.0001^{*}$ \\
Group B & $0.62 \pm 0.32$ & $0.38 \pm 0.2$ & 0.24 & $38.7 \%$ & $0.002^{*}$ \\
MD & 0.53 & 0.37 & & & \\
$p$-value & 0.059 & $0.04^{*}$ & & & \\
\hline
\end{tabular}

$\begin{array}{ll}* & : \text { Significant level is set at alpha level }<0.05 . \\ \text { SD } & : \text { Standard Deviation. } \\ \text { MD } & : \text { Mean Difference. } \\ p \text {-value } & \text { : Probability value. }\end{array}$

\section{3- Absolute Rotator Angle (ARA):}

1- Within groups: As presented in (Table 5) within group's comparison the mean \pm SD values of ARA in the "pre" and "post" tests were $36.07 \pm$ 2.09 and $41.64 \pm 3$ respectively in the group (A). Multiple pairwise comparison tests (post hoc tests) revealed that there was significant increase of ARA at post-treatment in compare to pre-treatment ( $p$ value $=0.0001 *)$. While, the mean $\pm \mathrm{SD}$ values of ARA in the "pre" and "post" tests were $36.33 \pm 1.71$ and $57.8 \pm 5.38$ respectively the group (B). Multiple pairwise comparison tests (post hoc tests) revealed 
that there was significant increase of ARA at posttreatment in compare to pre-treatment $(p=0.0001 *)$.

2- Between groups: Considering the effect of the tested group (first independent variable) on ARA, multiple pairwise comparison tests (post hoc tests) revealed that the mean values of the "pre" test between both groups showed no significant differences with $(p=0.715)$. As well as, multiple pairwise comparison tests (post hoc tests) revealed that there was significant difference of the mean values of the "post" test between both groups with $(p=0.0001 *)$ and this significant increase in favor to group B than group A.

Table (5): Mean \pm SD and $p$-values of ARA pre and post-test at both groups.

\begin{tabular}{llllll}
\hline ARA & $\begin{array}{c}\text { Pre test } \\
\text { Mean } \pm \text { SD }\end{array}$ & $\begin{array}{c}\text { Post test } \\
\text { Mean } \pm \text { SD }\end{array}$ & MD & $\begin{array}{c}\% \text { of } \\
\text { change }\end{array}$ & $\begin{array}{c}p \text { - } \\
\text { value }\end{array}$ \\
\hline Group A & $36.07 \pm 2.09$ & $41.64 \pm 3$ & -5.57 & $15.44 \%$ & $0.0001 *$ \\
Group B & $36.33 \pm 1.71$ & $57.8 \pm 5.38$ & -21.47 & $59.09 \%$ & $0.0001 *$ \\
MD & -0.26 & -16.16 & & & \\
$p$-value & 0.715 & $0.0001 *$ & & & \\
\hline
\end{tabular}

$\begin{array}{ll}* * & : \text { Significant level is set at alpha level }<0.05 . \\ \text { SD } & : \text { Standard Deviation. } \\ \text { MD } & \text { : Mean Difference. } \\ p \text {-value : Probability value. }\end{array}$

\section{Discussion}

Abnormal posture or any deviation from normal spinal alignment causes increased stress on the spinal cord [20]. The stresses and strains in the neural elements and vascular supply are directly related to the function of the sensory, motor, and autonomic nervous systems. Prolonged loading of the neural tissue may lead to a wide variety of degenerative disorders or symptoms [21]

The Denneroll is a spinal remodeling device used to help restore proper sagittal plane spinal curvature and correct other conditions. The Denneroll products are patent pending designs which are specific to each region of the spine (cervical, thoracic and lumbar), with precisely engineered contours, carefully tested firmness and flexibility, to enhance treatment. Lumbar spine was assigned to the patient in this study [22]

This study demonstrates that the group receiving lumbar Dennroll extension traction in addition to U.S therapy, I.R.R and stretching exercises showed more improvement than the control group in clinical, mechanical and neurophysiological parameters based on H-reflex, H/M ratio and ARA measurements. Furthermorethese results provide objective evidence that ARA dysfunction in terms of lumbar curve malalignment, and not just pathoanatomy, influences outcome measures [23].
The improvement in lumbar lordosis recorded by the study group is similar to that reported in a case study that showed the effectiveness of extension traction on restoring lumbar sagittal spinal configuration [24]. Another study by [25] concluded that lumbar extension traction with stretching exercises and infrared radiation was superior to stretching exercises and infrared radiationalone for improving the sagittal lumbar curve, pain, and intervertebral movement in CMLBP.

Stretching of the viscous and plastic elements of the longitudinal ligament and intervertebral disc may be the possible explanation for restoring the normal lumbar lordosis. Overall, our results are conceptually in agreement with other studies that have identified the strong association between sagittal alignment and back pain [26] .

In contrast, these findings contradicted those of many authors who investigated the relationship between lumbar lordosis and pain and reported no significant correlation between them [16]. The reasons for these differences may be related both to the initial selection of patients with relatively small numbers, and to the fact that all of these studies were correlational studies and not true experimental studies; that is, they look for a degree of association between variables without the ability to ascribe cause and effect [27].

With regard to the outcomes, the improvement of measured parameters and lumbar mobility compared with the control group are in agreement with those of Miyakoshi et al., who reported that lumbar lordosis restoration was an important factor in improving spinal function. In contrast, the systematic review of [28].

This contradiction may be attributed to different reasons: First, the low methodological quality of included studies. The systematic review of Christensen and Hartivigsen included all types of sagittal plane curvature measurement methods. We found that several studies were using a flexicurve (flexible ruler) to measure lumbar lordosis via sagittal skin contour. Interestingly, flexicurve measurement of lumbar lordosisis not externally valid and not useful for making legitimate decisions regarding the state of lumbar lordosis [28]

The second issue relates to the vague inclusion and exclusion criteria for patient selection. Another outcome assessment that has been investigated in the present study was restoring curve of lumbar vertebrae. Our findings that "lumbar extension traction had a significant and stable effect on intervertebral movements for the most levels com- 
pared with the control group" are in agreement with those of [29], who reported that 'proper mechanical alignment is essential for joint function'.

These findings are aligned with those of [30], who indicated that spinal posture is one of the most common factors affecting the coupled movements of spinal vertebrae [31]. This concept was further supported by Keorochana et al., who stated that 'sagittal alignment, disc degeneration, and segmental mobility likely have a reciprocal influence on one another' [32].

The majority of included studies employed traction on patients that suffered nerve root compression symptoms (radiculopathy, sciatica, discogenic pain). In their randomized clinical trial, aims to investigate the effects of lumbar extension traction in patients with unilateral lumbosacral radiculopathy due to L5-S1 disc herniation. All patients had also hypolordotic lumbar spine ARA $\left(<39^{\circ}\right)$. The control group received hot packs and interferential therapy, whereas the traction group received lumbar extension traction in addition to hot packs and interferential therapy. They concluded that traction group had better effects than the control one with regard to pain, disability, H-reflex parameters and segmental intervertebral movements [25]

Neurophysiologically, the significant and persistence changes in H-reflex parameters (decrease in H-reflex latency and increase in H-reflex amplitude) in the traction group compared with the control group could indicate that a normal lumbar lordotic curve is essential for normal neural function. Restoring the normal mechanics for the nervous system and decreasing the abnormal stresses and strains on neural elements are the likely explanation for significant improvement in H-reflex parameters. This concept showed how loss of the lumbar curve alters the mechanical properties of the spinal cord and nerve root that may change the firing patterns of involved neurons [33]

The unique contribution of our study is that it evaluated the independent effects of structural rehabilitation in the form of lumbar lordosis correction on ARA and neurophysiological findings, which to our knowledge have not been previously reported. In conclusion, the findings of the current study might serve to reinforce the importance of using structural rehabilitation in the form of restoring the normal lumbar lordotic curvature in management of low back pain patients. Interestingly, restoring the normal curve introduces yet another treatment option to a list that already includes physical agent modalities and manual therapies such as massage and myofascial stretch. Its unique appeal lies in its long lasting effect. These observed effects should be of value to clinicians and health professionals involved in the treatment of spinal disorders [18].

Certain limitations of the present study are worthy of mention. The primary limitation was the kinematic analysis nature of the spine. Furthermore, due to the type of intervention, it was not possible to blind the physiotherapist who provided the interventions. With regard to the initial selection of the patients, they probably represented a convenient sample rather than a random sample of the whole population.

The control group did not receive the same form of time-consuming treatment. Since this trial was conducted in a clinical setting with the majority of participants referred by medical practitioners for physiotherapy treatment, it was not possible to incorporate a control group that did not receive physiotherapy intervention. The patients were selected according to absolute rotatory angle only, ignoring the role of relative rotatory angle between adjacent vertebrae. This may be the main cause for the inconsistency of results for certain levels. No attempt was made to control for medications taken by participants, which included opioid and non-opioid analgesics and non-steroidal antiinflammatory drugs.

However, medication use was similar at baseline and no significant difference was found between the groups for number of participants who were managing their pain with medication immediately after the 10-week intervention. Future randomized trials should be conducted on a randomly selected sample using non-invasive methods such as a motion analysis system. Traction mechanism to relieve pain seems to separate the vertebrae, remove pressure or contact forces from injured tissue, increase peripheral circulation by a massage effect, and reduce muscle spasm [17]

The aim of the currentstudy is to discuss and analyze the latest result regarding lumbar traction by Denneroll in order to clarify some aspects of this specific and useful physical therapy toll. This study had several strengths, including that it was analysed using the intention-to-treat principle and that participants were assigned randomly to experimental and control groups. Also, interventions were provided by the same experienced physiotherapist. In addition, participants in both intervention groups received the same number of interventions. 


\section{Clinical messages:}

Lumbar Denneroll extension traction is beneficial in restoring lumbar lordosis. Restoring of lumbar lordosis seems to be effective in patients who have low back pain, with respect to pain, mechanical, clinical and functional status outcomes.

\section{References}

1- CASTELLINI G., GIANOLA S., BANFI G., BONOVAS S. and MOJA L.: "Mechanical low back pain: Secular trend and intervention topics of randomized controlled trials". Physiotherapy Canada; 68 (1): 61-3, 2016.

2- COSTA L.O., MAHER C.G., LOPES A.D., NORONHA M.A. and COSTA L.: "Transparent reporting of studies relevant to physical therapy practice". Brazilian Journal of Physical Therapy, 15 (4): 267-71, 2011.

3- HOY D.: "The global burden of low back pain: Estimates from the Global Burden of Disease study". Arch. Phys. Med. Rehabil., 218-22, 2010.

4- PRANSKY G., BUCHBINDER R. and HAYDEN J.: "Contemporary low back pain research-and implications for practice". Best Pract. Res. Clin. Rheumatol., 24 (2): 291-8, 2010.

5- KELLER T.S., SZPALSKI M., GUNZBURG R. and SPRATT K.F.: "Assessment of trunk function in single and multi-level spinal stenosis: A prospective clinical trial". Clin. Biomech., 18: 173-81, 2003.

6- MAGORA A. and SCHWARTZ A.: "Relation between low back pain syndrome and X-ray findings". Scand. J. Rehabil. Med., 12: 47-52, 1980.

7- DENNEROLL.: [Cited 2013 May 7]. Available from: http://www.idealspine.com/denneroll/, 2013.

8- BEEN E. and KALICHMAN L.: "Lumbar lordosis". Spine J., 14: 87-97, 2014.

9- WEINSTEIN J.N., LURIE JD., TOSTESON T.D., HANSCOM B., TOSTESON A.N., BLOOD EA., BIRKMEYER N.J., HILIBRAND A.S., HERKOWITZ H., CAMMISA F.P., ALBERT T.J., EMERY S.E., LENKE L.G., ABDU W.A., LONGLEY M., ERRICO T.J. and HU S.S.: "Surgical versus nonsurgical treatment for lumbar degenerative spondylolisthesis". N. Engl. J. Med., 356: 2257-70, 2007.

10- WANG C., SCHMID C.H., RONES R., KALISH R., YINH J., GOLDENBERG D.L., LEE Y. and McALINDON T.: "A randomized trial of tai chi for fibromyalgia". N. Engl. J. Med., 363 (8): 743-54, 2010.

11- BAEK S.O., AHN S.H. and JONES R.: "Activations of deep lumbar stabilizing muscles by transcutaneous neuromuscular electrical stimulation of lumbar paraspinal regions". Ann. Rehabil. Med., 38: 506-13, 2014.

12- BILGIN S., TEMUCIN C.M., NURLU G., KAYA D.O., KOSE N. and GUNDUZ A.G.: "Effects of exercise and electrical stimulation on lumbar stabilization in asymptomatic subjects: A comparative study". J. Back. Musculoskelet. Rehabil., 26: 261-6, 2013.

13- DESAI H.S. and BISEN R.S.: "Lumbar flexion relaxation phenomenon in the patients with acute and subacute mechanical low back pain and normal subjects". Inter. J. of Res. in Med. Sci., 5 (3): 1011-4, 2017.
14- SADIQI S., VERLAAN J.J., LEHR A.M., DVORAK M.F., KANDZIORA F., RAJASEKARAN L. and ONER F.C.: "Universal disease-specific outcome instruments for spine trauma: A global perspective on relevant parameters to evaluate clinical and functional outcomes of thoracic and lumbar spine trauma patients". European Spine Journal, 26 (5): 1541-9, 2017.

15- LINDGREN K., SIHVONEN T., LEINO E. and PITKANEN M.: "Exercise therapy effects on functional radiographic findings and segmental electromyographic activity in lumbar spine instability". Arch. Phys. Med. Rehabil., 74: 933-9, 1993.

16- HARRISON D.E., HARRISON D.D., CAILLIET R., JANIK T.J. and HOLLAND B.: "Changes in Sagittal Lumbar Configuration with a New Method of Extension Traction: Non-randomized Clinical Control Trial". Arch. Phys. Med. Rehab., 83 (11): 1585-91, 2002.

17- ONER F.C., SADIQI S., LEHR A.M., DVORAK M.F., AARABI B., CHAPMAN J.R., FEHLINGS M.G., KANDZIORA F., RAJASEKARAN S. and VACCARO A.R.: "Towards the development of an outcome instrument for spinal trauma: An international survey of spinal surgeons". Spine, 40: 91-6, 2015.

18- HONG J.Y., SUH S.W., YANG J.H., PARK S.Y. and HAN J.H.: "Reliability analysis of shoulder balance measures: Comparison of the 4 available methods". Spine, 38 (26): 1684-90, 2013.

19- FISHER M.A.: "H reflexes and F waves: Physiology and clinical indications". Muscle Nerve, 15: 1223-33, 1992.

20- GIBSON J.N. and WADDELL G.: "Surgery for degenerative lumbar spondylosis". Cochrane Database Syst. Rev., 2: 52, 2005.

21- JOAQUIM A.F., DAUBS M.D., LAWRENCE B.D., BRODKE D.S., CENDES F., TEDESCHI H. and PATEL A.A.: "Retrospective evaluation of the validity of the Thoracolumbar Injury Classification System in 458 consecutively treated patients". Spine, 13: 1760-5, 2013.

22- HARRISON D.D.: "Spinal biomechanics: A chiropractic perspective". National Library of Medicine, 91-7, 1982.

23- LINLEY S.E., PETERSON J., MASTROPOLO R., ROBERTS T., LAWRENCE J. and GLENNON J.: "Mechanical loading rate modulates intervertebral disc trans-endplate transport". Ortho. Res. Socie., 28-36, 2013.

24- NEGRINI S., ANTONINI G., CARABALONA R. and MINOZZI S.: "Physical exercises as a treatment for adolescent idiopathic scoliosis. A systematic review". Pediatr. Rehabil., 6: 227-35, 2003.

25- MOUSTAFA I.M. and DIAB A.A.: "Extension traction treatment for patients with discogenic lumbosacral radiculopathy: A randomized controlled trial". Clin. Rehab., 27 (1): 56-68, 2012.

26- FERRANTELLI J.R., HARRISON D.E., HARRISON D.D. and STEWART D.: "Conservative treatment of a patient with previously unresponsive whiplash-associated disorders using clinical biomechanics of posture rehabilitation methods". J. Mani. Physio. Ther., 28 (3): 2051-8, 2005.

27- GLASSMAN S.D., BRIDWELL K., DIMAR J.R., HORTON W., BERVEN S. and SCHWAB F.: "The impact of 
positive sagittal balance on adult spinal deformity". Spine, 30 (18): 2024-9, 2005.

28- GALE G.D., ROTHBART P.J. and LI Y.: "Infrared therapy for chronic low back pain: A randomized, controlled trial". Pain Res. Manage., 11 (3): 193-6, 2006.

29- DARNELL M.W.: "Proposed chronology of events for forward head posture". J. Craniomandib. Pract., 1: 4954, 1983.

30- PANJABI M.M. and WHITE A.A.: "Basic biomechanics of the spine". Neurosurgery, 7 (1): 76-93, 1980.

31- MIYAKOSHI N., M. KASUKAWA M.Y., ISHIKAWA Y. and SHIMADA Y.: "Prevalence, Spinal Alignment, and Mobility of Lumbar Spinal Stenosis with or without Chronic Low Back Pain: A Community-Dwelling Study Pain Research and Treatment". Spine; 24-30, 2011.

32- KEOROCHANA G., TAGHAVI C., LEE K., YOO J., LIAO J., FEI Z. and WANG J.: "Effect of Sagittal Alignment on Kinematic Changes and Degree of Disc Degeneration in the Lumbar Spine: An Analysis Using Positional MRI". Spine, 36 (11): 893-8, 2011.

33- HARRISON D.E., CAILLIET R., HARRISON D.D. TROYANOVICH S.J. and HARRISON S.O.: "A review of biomechanics of the central nervous system--Part I: Spinal canal deformations resulting from changes in posture". J. Mani. Physio. Ther., 22 (4): 227-34, 1999.

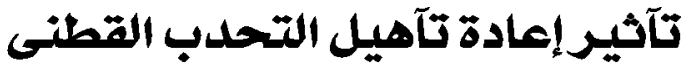

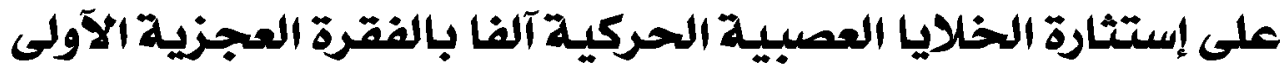

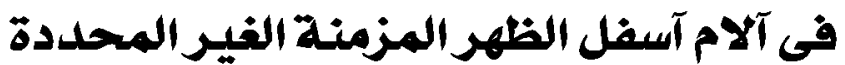

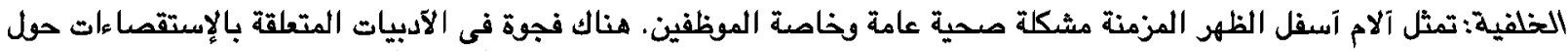

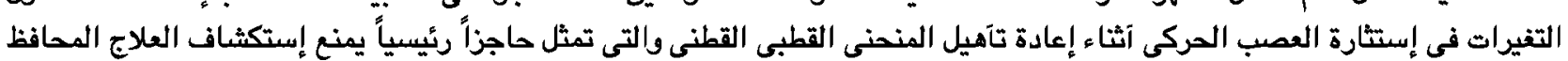

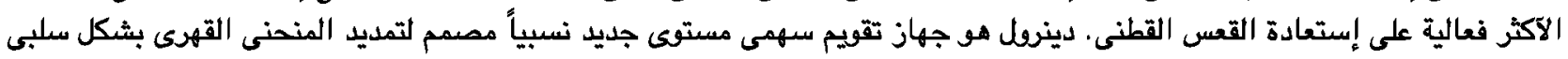
إلى وضع آكثر قوة.

الهدف من الرسالة: صممت هذه الدراسة لدراسة تآثير جر دينيرل القطنى على إستثارة العصب الحركى على مرضى آلام آسفل الظهر

المـادة والطرق: شارك ثلاثق مريضاً في هذه الدراسة. تم تعيينهم بشكل عشوائى إلى مجموعتين (آ) مجموعة تجريبية، و (ب) مجموعة

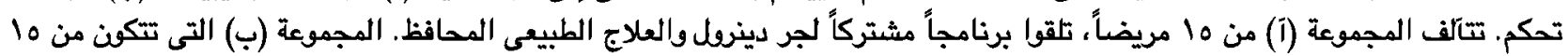

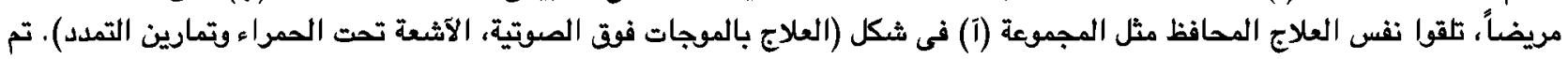

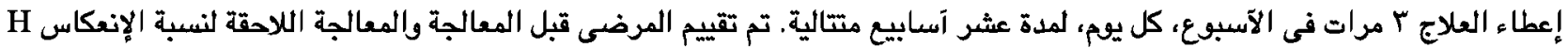
ونسبة H/M وذاوية الدوان المطلقة فئة

النتأج : بإستخدام مقاييس متكرة تعليل متعدد المتغيرات لإختبار التباين (MANOVA)، آظهر المرضى تصسناً كبيراً فى المتغيرات

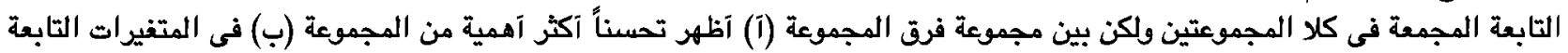

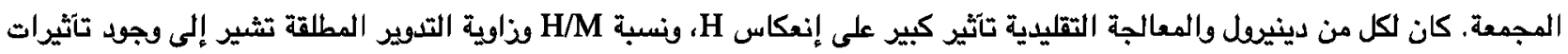

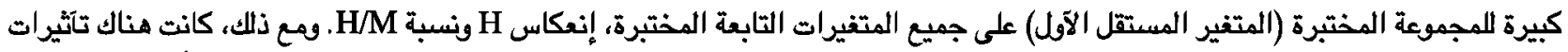

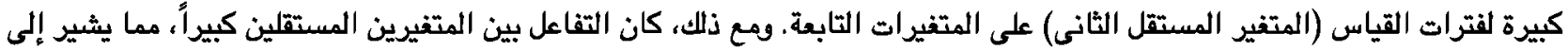
آن تآثير المجموعة المختبرة (المتفير المستقل الآتل) على المتفيرات التابعة قد تآثر بفترات القياس (المتفير المستقل الثانى).

الإستتاج: لذلك، فإن الجمع بين دينرول وبرنامج العلاج الطبيعى التقليدى آكثر فعالية من التمارين العلاجية وحدها فى علاج مرضى آلام 